\title{
Comparison of pharmacokinetic characteristics of two Tegoprazan (CJ-12420) formulations in healthy male subjects
}

\author{
Jun Gi Hwang ${ }^{1}$, Hyounggyoon Yoo ${ }^{1}$, Ji Won Lee ${ }^{2}$, Geun Seog Song ${ }^{2}$, SeungHwan Lee ${ }^{1}$ and Min-Gul Kim ${ }^{3 *}$ \\ ${ }^{1}$ Department of Clinical Pharmacology and Therapeutics, Seoul National University College of Medicine and Hospital, Seoul 03080, \\ Republic of Korea, ${ }^{2}$ Clinical Development Division, CJ HealthCare Corp., Seoul 04551, Republic of Korea, ${ }^{3}$ Department of Pharmacology, \\ School of Medicine, Chonbuk National University, Jeonju 54907, Republic of Korea \\ ${ }^{*}$ Correspondence: M. G. Kim; Tel: +82-63-259-3480, Fax: +82-63-259-3483, E-mail: mgkim@jbnu.ac.kr
}

\section{Check for updates}

Received 25 Apr 2019

Revised 13 Jun 2019

Accepted 19 Jun 2019

\section{Keywords}

Bioequivalence,

Clinical trial,

Pharmacokinetics,

Phase 1

pISSN: 2289-0882

eISSN: 2383-5427
Proton-pump inhibitors (PPIs) are effectively used to treat acid-related diseases, including gastroesophageal reflux disease (GERD); however, many unmet medical needs still exist. As a new treatment option, potassium-competitive acid blockers (P-CABs), such as tegoprazan, have been developed. This study was performed to compare the pharmacokinetics (PKs) between two formulations (test and reference drugs) of tegoprazan $100 \mathrm{mg}$ tablets. A randomized, single oral dose, two-treatment, two-period, two-sequence study was conducted with 12 healthy subjects. Each subject received the test drug or reference drug in the first period and the alternative treatment in the second period. For PK evaluation, blood samples were collected up to 48 hours post-dose in each period. The plasma concentrations of tegoprazan and its active metabolite (M1) were measured by liquid chromatography-tandem mass spectrometry. PK parameters, including maximum plasma concentration $\left(\mathrm{C}_{\max }\right)$ and area under the concentration-time curve from zero to the last measurable time $\left(\mathrm{AUC}_{\text {last }}\right)$, were estimated using a non-compartmental method. The plasma concentrationtime profiles of the two formulations were comparable. The geometric mean ratios $[90 \%$ confidence intervals (CIs)] of the test drug to the reference drug for $\mathrm{C}_{\max }$ and $\mathrm{AUC}_{\text {last }}$ were $0.98(0.85-1.12)$ and 1.03 (0.93-1.13), respectively. The corresponding values of M1 were $0.99(0.89-1.11)$ and 1.01 (0.93-1.09), respectively. The two formulations of tegoprazan exhibited comparable PK profiles, fulfilling the regulatory criteria for bioequivalence.

\section{Introduction}

Gastroesophageal reflux disease (GERD) is one of the most common gastrointestinal disorders.[1] The clinical symptoms of GERD are defined as experiencing heartburn and acid regurgitation at least once a week. The prevalence of GERD among the adult population in East Asia is 2.5-7.8\%.[1] Peptic ulcer disease is another gastrointestinal disorder known by its high

Copyright ( 2019 Translational and Clinical Pharmacology

(a) It is identical to the Creative Commons Attribution Non-Commercial License (http://creativecommons.org/licenses/by-nc/3.0/).

@ This paper meets the requirement of KS X ISO 9706, ISO 9706-1994 and ANSI/NISO Z.39.48-1992 (Permanence of Paper).

Reviewer

This article was reviewed by the peer experts who are not TCP editors. prevalence and chronic nature.[2,3]

Proton-pump inhibitors (PPIs) reduce gastric acid secretion by inhibiting $\mathrm{H}^{+} / \mathrm{K}^{+}$-ATPase of parietal cells. [4] Since their approval in 1998, PPIs have been widely used to treat acid-related diseases such as GERD and peptic ulcer. Although PPIs have been proved to be safe and effective, quite a large number of patients failed to respond to the treatment.

The use of PPIs poses some limitations. Firstly, PPIs cause nocturnal acid breakthrough even in patients who take PPIs with long half-life or twice daily.[5] Secondly, PPIs exhibit delayed onset time because they require conversion to the active form. [6] PPIs undergo molecular rearrangement under the acidic condition,[7] and the binding of active form with the receptor is irreversible. For this reason, taking PPIs before a meal is recommended, which may result in poor compliance of the patient.[8] 
Thirdly, there are many cases of rebound acid secretion after cessation of PPIs. While rebound acid secretion can occur after withdrawal of any acid-suppressive drugs, PPIs induce more extended rebound period than antacids or $\mathrm{H} 2$ antagonists.[9] In order to overcome the limitations of conventional PPIs, the development of new types of a drug for the treatment of acidrelated diseases is expected.[10]

Potassium-competitive acid blockers (P-CABs) are one of the novel drugs developed for the suppression of gastric acid secretion. $\mathrm{P}-\mathrm{CAB}$ inhibits $\mathrm{H}^{+} / \mathrm{K}^{+}$-ATPase by binding to the potassium-binding site. $\mathrm{P}-\mathrm{CABs}$ have a fast onset of action because they bind to both active and inactive forms of $\mathrm{H}^{+} / \mathrm{K}^{+}$ATPase, indicating that they do not need acid activation. Owing to these advantages, $\mathrm{P}$-CABs shows faster gastric $\mathrm{pH}$ inhibition and have the potential to show a clear pharmacokinetic (PK)pharmacodynamic (PD) relationship than PPIs. $[4,10,11]$

Tegoprazan is a novel $\mathrm{P}-\mathrm{CAB}$ that has high selectivity towards $\mathrm{H}^{+} / \mathrm{K}^{+}$-ATPase ( $\mathrm{IC}_{50}$ of $0.47 \mu \mathrm{M}$ in ion-leaky vesicles). In a phase $\mathrm{I}$, single ascending dose study, tegoprazan reached a mean $\mathrm{T}_{\max }$ at 0.5 to $1.5 \mathrm{~h}$ after dosing, and the mean elimination half-life $\left(\mathrm{t}_{1 / 2}\right)$ was 3.65 to $5.39 \mathrm{~h} . \mathrm{C}_{\max }$ and $\mathrm{AUC}_{\text {last }}$ exhibited a dose-dependent increase. Tegoprazan was expected to be metabolized by CYP3A in humans and produce its major demethylated metabolite M1.[12] In order to improve the productivity and stability of tegoprazan, conducting new formulation studies were needed.

The objective of the present study was to compare PK between the two formulations of tegoprazan film-coated $100 \mathrm{mg}$ tablets in healthy Korean male subjects.

\section{Method}

\section{Subjects and Study design}

This study was approved by Korea Ministry of Food and Drug Safety and the Institutional Review Board of Chonbuk National University Hospital, Jeonju, Republic of Korea. This study was conducted at Chonbuk National University Hospital following the ethical principles of the Declaration of Helsinki and rules of Korean Good Clinical Practices. Written informed consent from each participant was obtained prior to being enrolled.
Healthy Korean male volunteers, aged 19 to 45 years with weight $>50 \mathrm{~kg}$, were enrolled in this randomized, single oral dose, 2-sequence, 2-period, crossover study. Their health status was determined based on medical history within 3 years, physical examination including vital sign measurements, 12-lead electrocardiogram (ECG), serology and routine clinical laboratory testing (including biochemistry, hematology, and urinalysis) conducted within 3 weeks before the initiation of the study. The subjects were excluded if they had a history of symptomatic gastroesophageal reflux disease, erosive esophagitis, duodenal ulcer, gastric ulcer, Barrett's esophagus, or Zollinger-Ellison syndrome.

Twelve eligible subjects were randomly assigned to two sequence groups. Subjects in one sequence group were given the test formulation in period 1 , followed by the reference formulation in period 2, and the other sequence group was given the reference formulation in period 1 , followed by the test formulation in period 2 (Fig. 1). There was a washout period of 7-10 days between the successive treatment periods, and the duration was determined considering the reported half-life of tegoprazan (3.84-6.46 h).[12]

\section{Determination of plasma concentration}

Blood samples for PK evaluation were obtained at pre-dose and $0.25,0.51,1.5,2,3,4,6,8,12,24$, and $48 \mathrm{~h}$ post-dose. At each blood sampling point, $8 \mathrm{~mL}$ of blood was collected in heparinized tubes and centrifuged for $10 \mathrm{~min}$ at $3000 \mathrm{rpm}$. After centrifugation, plasma was separated and stored at $-70^{\circ} \mathrm{C}$ until analysis.

The plasma concentrations of tegoprazan and M1 were determined by ultra performance liquid chromatography (UPLC) coupled with a tandem mass spectrometry method. Plasma samples were centrifuged at 13,000 rpm for $3 \mathrm{~min}$. One hundred $\mu \mathrm{L}$ of plasma was mixed with $10 \mu \mathrm{L}$ of internal standard (IS; tegoprazan $2 \mathrm{ug} / \mathrm{mL}$ in $50 \%$ methanol), then mixed at 1,500 rpm using Mixmate and centrifuged at 4,000 rpm for $1 \mathrm{~min}$. It was mixed with methanol $400 \mu \mathrm{L}$ then mixed at $1,500 \mathrm{rpm}$ using Mixmate and centrifuged at 4,000 rpm for 1 min again. One hundred $\mu \mathrm{L}$ of upper layer solution added $300 \mu \mathrm{L}$ of a mixture of methanol : DW : formic acid $(30: 70: 0.1)$ centrifuged at 4,000

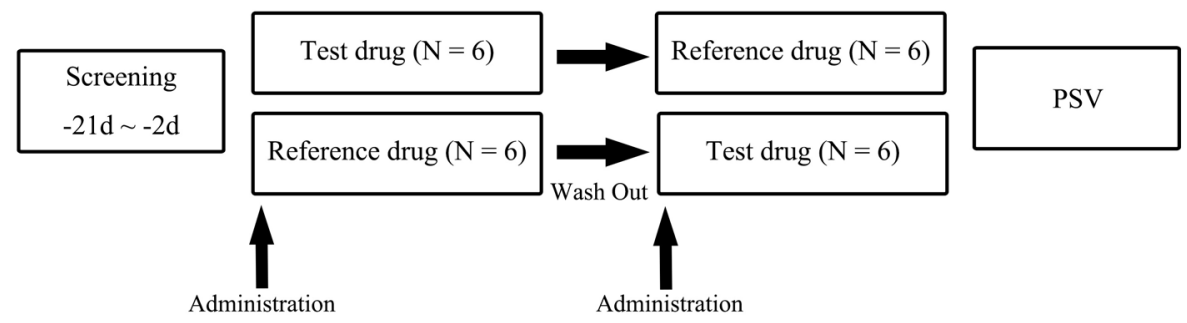

Figure 1. Study design. (Reference drug = tegoprazan formulation 1, Test drug = tegoprazan formulation 2). Six subjects were allocated to each sequence group. 
rpm for $1 \mathrm{~min}$ twice. Then $0.5 \mu \mathrm{L}$ mixture was injected onto the UPLC-MS/MS. Linear calibration curves for tegoprazan were established from 20 to $10,000 \mathrm{ng} / \mathrm{mL}$ ( $\mathrm{r} 2 \geq 0.9995)$. Within-run and between-run precision and accuracy were determined by five repeated analyses of each quality control sample on day 1 . Inter-day precision and accuracy were determined by repeated analyses on four consecutive days using 20,60,5000, and 7500 $\mathrm{ng} / \mathrm{mL}$ of tegoprazan. Within-run and between-run precision (relative standard deviation) for tegoprazan were $1.3-4.1 \%$ and 2.3-8.4\%, respectively. The corresponding values for M1 were $0.9-5.4 \%$ and $3.2-10.4 \%$, respectively. Within-run and between-run accuracy (deviation of the mean from theoretical) for tegoprazan were $-0.6--10.0 \%$, and $-1.9-2.0 \%$, respectively. The corresponding values for M1 were $-4.0-14.0 \%$ and $-2.1-6.0$ $\%$, respectively.

\section{PK evaluation}

The PK parameters were determined using a non-compartmental method implemented in Phoenix ${ }^{\circ}$ WinNonlin ${ }^{\circ} 6.2$ (Certara, L.P., St. Louis, MO, USA). The maximum plasma concentration $\left(\mathrm{C}_{\max }\right)$ and time to reach $\mathrm{C}_{\max }\left(\mathrm{T}_{\max }\right)$ were determined directly from the observed individual plasma concentrationtime profiles. Terminal elimination half-life $\left(t_{1 / 2}\right)$ was calculated as the natural logarithm of 2 divided by $\lambda_{L}$, which is the terminal elimination rate constant estimated in the linear portion of the decline of natural logarithmic-transformed individual plasma concentrations. The area under the concentration-time curve (AUC) from dosing to the last quantifiable concentration (AU$\mathrm{C}_{\text {last }}$ ) was calculated using the linear trapezoidal method, and AUC from dosing to infinity $\left(\mathrm{AUC}_{\text {inf }}\right)$ was calculated as the sum of $\mathrm{AUC}_{\text {last }}$ and $\mathrm{C}_{\mathrm{t}} / \lambda_{\mathrm{r}^{\prime}}$. CL/F was defined as an apparent total clearance of the drug from plasma after oral administration, and $\mathrm{Vd} /$ F was defined as an apparent volume of distribution after nonintravenous administration.

\section{Safety/tolerability evaluation}

The safety and tolerability of all subjects, who administered at least one time of investigational products were included in the safety analysis, based on the occurrence of adverse events (AEs), vital signs, clinical laboratory evaluations, ECG, and physical examination throughout the study period.

All adverse events were summarized by subjects, percentage, and frequency of occurrence and presented using descriptive statistics. Adverse events were coded with system organ classes and preferred terms. Laboratory results, vital signs, and ECG findings were reviewed for each subject and clinically significant results were summarized by treatment arms and time points using descriptive statistics. Findings from the physical examination were also reviewed in order to examine the existence of clinical significance or any association with the administration of the investigational products.

\section{Statistical analysis}

All statistical analyses were performed using SAS 9.4 (SAS Institute, Cary, NC, USA), and $P$-values $\leq 0.05$ were considered statistically significant. Descriptive statistics were used to summarize the demographics and PK parameters. To compare the PK parameters, point estimates and 90\% CIs of the geometric least squares mean ratio (GMR) (test treatment/reference treatment) of the log-transformed $\mathrm{C}_{\max }$ and $\mathrm{AUC}_{0 \text {-last }}$ were also presented. The demographic characteristics were compared between the two sequence groups using independent $\mathrm{t}$-tests. Bioequivalence was assessed if $90 \% \mathrm{CI}$ of $\mathrm{GMR}$ for $\mathrm{C}_{\max }$ and $\mathrm{AUC}_{0 \text {-last }}$ fell within the conventional bioequivalence range of 0.8-1.25.

\section{Results}

\section{Subjects}

All 12 subjects who were enrolled successfully completed the study. The mean \pm standard deviation of age, height, body weight and BMI of the subjects were $23.9 \pm 1.3$ years, $173.1 \pm$ $7.6 \mathrm{~cm}, 68.4 \pm 8.2 \mathrm{~kg}$, and $22.8 \pm 2.2$, respectively. There were no clinically relevant differences between the two sequences in any of the demographic characteristics (Table 1).

\section{Pharmacokinetics}

The mean plasma tegoprazan concentration-time profiles of the two formulations after a single oral dose were comparable, including both absorption and disposition phases (Fig. 2). Both formulations were absorbed rapidly with a median $\mathrm{T}_{\max }$ of 0.83 and $0.71 \mathrm{~h}$ for the test and reference drugs, respectively. The $\mathrm{C}_{\max }$ (mean $\pm \mathrm{SD}$ ) values for the test and reference drugs were $1,434.50 \pm 570.82$ and $1,415.92 \pm 326.78 \mu \mathrm{g} / \mathrm{L}$, respectively, and the corresponding values for $\mathrm{AUC}_{\text {last }}$ were $5720.00 \pm 1417.86$

Table 1. Demographics of study participants administered test and reference formulations of $100 \mathrm{mg}$ tegoprazan tablets

\begin{tabular}{|c|c|c|c|c|}
\hline Variable & $\begin{array}{l}\text { Total } \\
(\mathrm{n}=12)\end{array}$ & $\begin{array}{c}\text { Sequence } A \\
(\text { Reference } \rightarrow \text { Test, } n=6 \text { ) }\end{array}$ & $\begin{array}{c}\text { Sequence } B \\
(\text { Test } \rightarrow \text { Reference, } n=6 \text { ) }\end{array}$ & $P$-value ${ }^{1)}$ \\
\hline Age (years) & $23.9 \pm 1.3(22.0-27.0)$ & $24.2 \pm 1.6(22.0-27.0)$ & $23.7 \pm 1.0(22.0-25.0)$ & 0.73 \\
\hline Height $(\mathrm{cm})$ & $173.1 \pm 7.6(162.1-184.6)$ & $174.2 \pm 8.2(165.0-184.0)$ & $172.0 \pm 7.6(162.1-184.6)$ & 0.64 \\
\hline Weight (kg) & $68.4 \pm 8.2(55.2-80.7)$ & $68.7 \pm 9.6(55.2-80.7)$ & $68.0 \pm 7.5(56.9-75.1)$ & 0.98 \\
\hline BMI $\left(\mathrm{kg} / \mathrm{m}^{2}\right)$ & $22.8 \pm 2.2(19.3-26.0)$ & $22.5 \pm 2.2(19.9-26.0)$ & $23.0 \pm 2.5(19.3-25.6)$ & 0.75 \\
\hline
\end{tabular}

${ }^{1)}$ Independent $t$-test. 

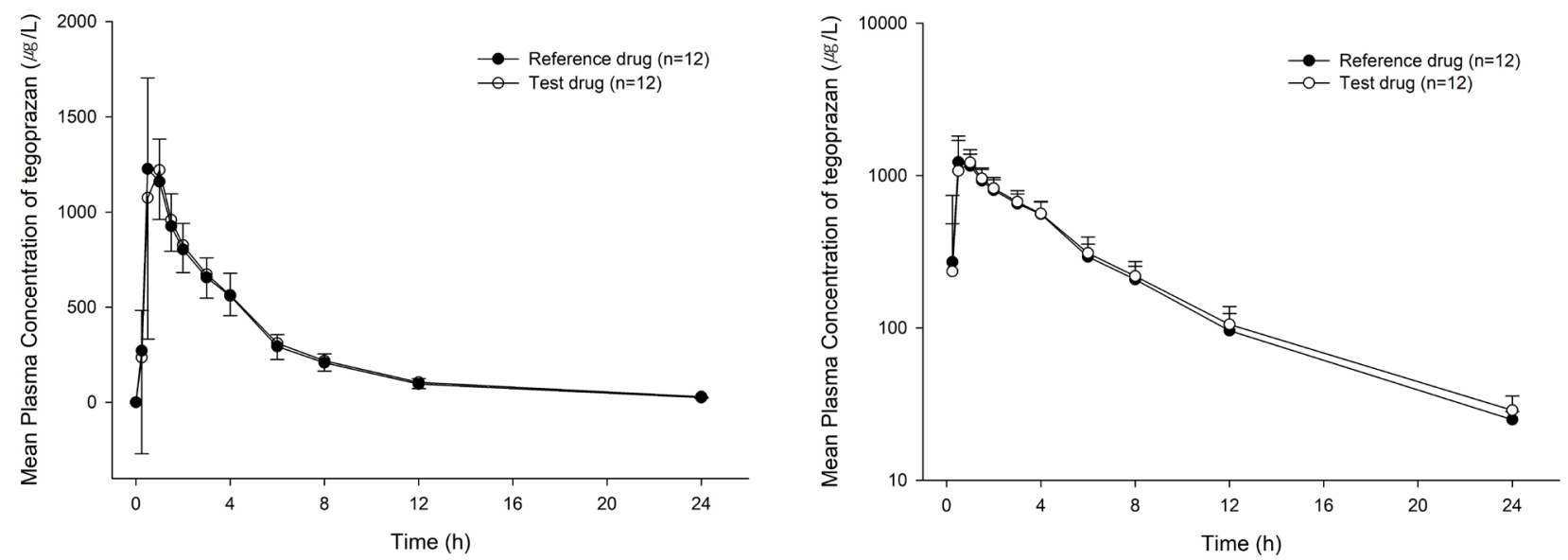

Figure 2. Mean plasma tegoprazan concentration-time profiles after a single oral dose of test or reference formulation of $100 \mathrm{mg}$ tegoprazan tablet (left: linear scale, right: semi-log scale).
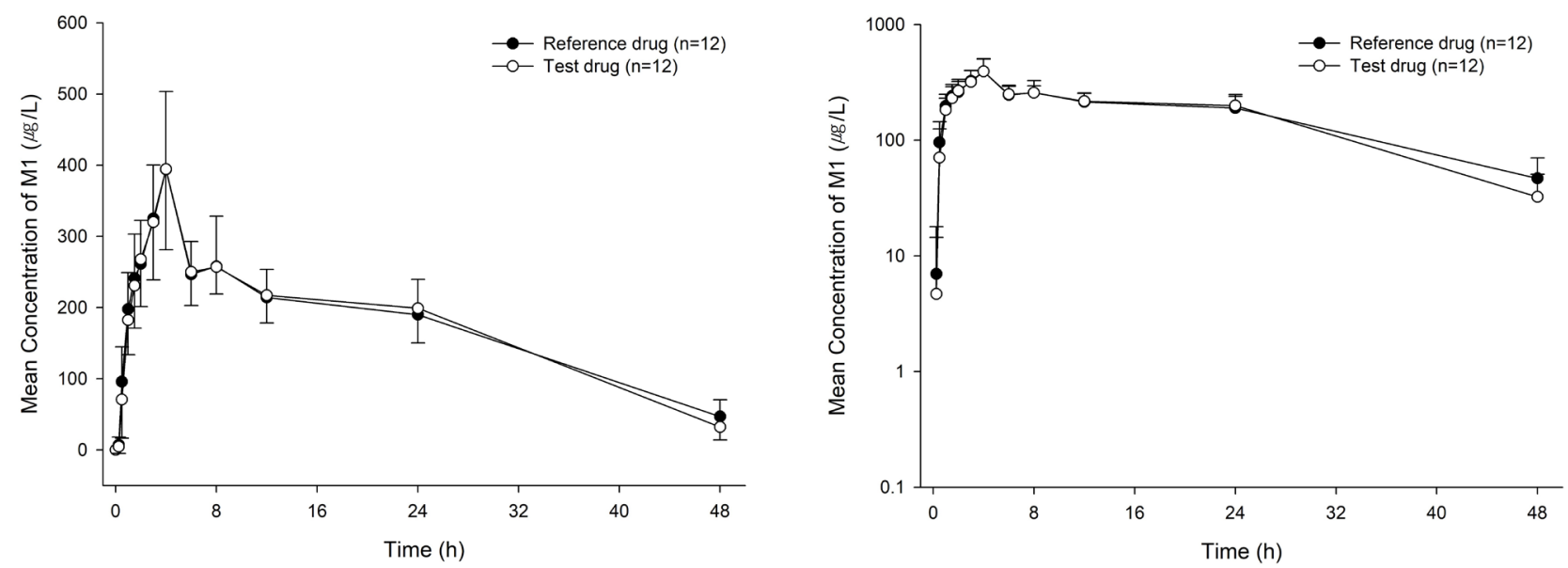

Figure 3. Mean plasma M1 concentration-time profiles after a single oral dose of test or reference formulation of 100 mg tegoprazan tablet (left: linear scale, right: semi-log scale).

Table 2. Pharmacokinetic parameters for test and reference formulations of $100 \mathrm{mg}$ tegoprazan tablets $(n=12)$

\begin{tabular}{|c|c|c|c|c|}
\hline Variable & Parameters & Test drug $(n=12)$ & Reference drug $(n=12)$ & GMR $(90 \% \mathrm{Cl})$ \\
\hline \multirow{7}{*}{ Tegoprazan } & $\mathrm{T}_{\max }(\mathrm{h})$ & $0.83 \pm 0.25$ & $0.71 \pm 0.26$ & - \\
\hline & $\mathrm{C}_{\max }(\mu \mathrm{g} / \mathrm{L})$ & $1,434.50 \pm 570.82$ & $1,415.92 \pm 326.78$ & $0.98(0.86-1.12)$ \\
\hline & $A \cup C_{\text {last }}\left(h^{*} \mu g / L\right)$ & $5,720.00 \pm 1,417.86$ & $5,502.99 \pm 1,070.62$ & $1.03(0.94-1.13)$ \\
\hline & $A \cup C_{\text {inf }}\left(h^{*} \mu g / L\right)$ & $5,998.13 \pm 1,379.16$ & $5,761.39 \pm 1,025.87$ & \\
\hline & $t_{1 / 2}(h)$ & $4.41 \pm 1.07$ & $4.08 \pm 0.85$ & \\
\hline & $\mathrm{CL} / \mathrm{F}(\mathrm{L} / \mathrm{h})$ & $17.58 \pm 4.48$ & $17.92 \pm 3.49$ & \\
\hline & $\mathrm{Vd} / \mathrm{F}(\mathrm{L})$ & $107.90 \pm 22.58$ & $103.31 \pm 19.25$ & \\
\hline \multirow{6}{*}{ M1 } & $\mathrm{T}_{\max }(\mathrm{h})$ & $4.33 \pm 1.15$ & $4.25 \pm 1.22$ & \\
\hline & $C_{\max }(\mu / L)$ & $396.67 \pm 108.67$ & $399.17 \pm 109.41$ & $0.99(0.89-1.11)$ \\
\hline & $\mathrm{AUC}_{\text {last }}\left(\mathrm{h}^{*} \mu / \mathrm{L}\right)$ & $8,328.93 \pm 1,351.80$ & $8,338.81 \pm 1,799.07$ & $1.01(0.93-1.09)$ \\
\hline & $A \cup C_{\text {inf }}\left(h^{*} \mu / L\right)$ & $9,125.80 \pm 1,660.49$ & $9,639.38 \pm 2,418.67$ & \\
\hline & $t_{1 / 2}(h)$ & $14.26 \pm 5.77$ & $16.89 \pm 5.48$ & \\
\hline & Metabolic ratio & $1.52 \pm 0.39$ & $1.44 \pm 0.31$ & \\
\hline
\end{tabular}


and 5,502.99 $\pm 1,070.62 \mu \mathrm{g}^{\star} \mathrm{h} / \mathrm{L}$, respectively. The GMR $(90 \%$ CIs) values of the test drug to the reference drug for $\mathrm{C}_{\text {max }}$ and $\mathrm{AUC}_{\text {last }}$ of tegoprazan were $0.98(0.86-1.12)$ and 1.03 (0.94-1.13), respectively (Table 2).

The mean plasma M1 concentration-time curves are shown in Figure 3. The PK parameters of M1 were comparable to each drug. The $\mathrm{C}_{\max }$ (mean $\pm \mathrm{SD}$ ) values for the test and reference drugs were $396.67 \pm 108.67$ and $399.17 \pm 109.41 \mu \mathrm{g} / \mathrm{L}$ respectively, and the corresponding values for $\mathrm{AUC}_{\text {last }}$ were 8,328.93 \pm $1,351.80$ and $8,338.81 \pm 1,799.07 \mu \mathrm{g}^{\star} \mathrm{h} / \mathrm{L}$, respectively. The GMR (90\% CIs) values of the test drug to the reference drug for $\mathrm{C}_{\max }$ and $\mathrm{AUC}_{\text {last }}$ of $\mathrm{M} 1$ were 0.99 (0.89-1.11) and 1.01 (0.93-1.09), respectively (Table 2).

Based on the Korea MFDS guidelines, the $90 \%$ CIs for the relevant $\mathrm{PK}$ parameters such as $\mathrm{C}_{\max }$ and $\mathrm{AUC}_{\text {last }}$ of both tegoprazan and M1 were within an acceptable range of $0.80-1.25$, indicating PK bioequivalence between both formulations.

\section{Safety and tolerability}

Subjects who administered at least one dose of the investigational products were included in the tolerability assessment. Both formulations of tegoprazan were well tolerated in every subject and no serious AEs were reported. White blood cells were detected from urine test in one subject, but the severity was mild, and the relationship with the investigational product was evaluated as unrelated. There were no other AEs throughout the clinical trial period. Clinically significant results were not observed by physical examination blood and urine tests, ECG tests, and vital signs.

\section{Discussion}

The object of the study was to compare the PK parameters and assess the bioequivalence of two formulations of tegoprazan. A new formulation has been developed and manufactured for improved productivity and stability compared to the conventional formulation.

This study was a randomized, single oral dose, 2 -sequence, 2-period, crossover design study, which is generally implemented for bioequivalence study. A total 12 of sample size achieved $80 \%$ power at a significance level of $\alpha=0.05$, when the percentage of the intra-individual coefficient of variation $(\mathrm{CV} \%)$ of $\mathrm{C}_{\max }$ and $\mathrm{AUC}_{\text {last }}$ of tegoprazan was 17.46 and $12.57 \%$, respectively.[13] The blood samples were obtained up to $48 \mathrm{~h}$ after dosing. With regard to the percentage of extrapolated $\mathrm{AUC}\left(\mathrm{AUC}_{\text {extra }}\right.$ $\%$ ), which is the marker of sufficient duration of evaluation, the $\mathrm{AUC}_{\text {extra }}$ of test and reference drugs was 4.97 and $4.74 \%$, respectively. These results imply that the sampling time points were appropriately selected to characterize the absorption and elimination phases of tegoprazan.

The washout period was 7-10 days. As washout period is usually determined as some multiple of the half-life of the drug and considering 3-6 $\mathrm{h}$ of the reported terminal half-life of tegoprazan,[12] 7-10 days were considered to be sufficient for the elimination of first administration prior to the second treatment period.[11]

The $\mathrm{C}_{\max }$ values (mean $\pm \mathrm{SD}$ ) for the test and reference drugs were $1,434.50 \pm 570.82$ and $1,415.92 \pm 326.78 \mu \mathrm{g} / \mathrm{mL}$, respectively, and the corresponding values of $\mathrm{AUC}_{\text {last }}$ for the test and reference drugs were $5,720.00 \pm 1,417.86$ and $5,502.99 \pm 1,070.62$ $\mu \mathrm{g} * \mathrm{~h} / \mathrm{mL}$, respectively. The PK parameters calculated in the present study were similar to those of a previous study.[12] Therefore, further studies will be designed for the test formulations of tegoprazan using obtained pharmacokinetic characteristics from this study.

In conclusion, this study showed that the PK parameters of the two tegoprazan formulations were comparable, and GMR (90\% CIs) for $\mathrm{C}_{\max }$ and $\mathrm{AUC}_{\text {last }}$ of both tegoprazan and $\mathrm{M} 1$ fell within the conventionally accepted bioequivalence criteria.

\section{Acknowledgments}

This study was sponsored by CJ HealthCare Corp., Seoul, Republic of Korea.

\section{Conflict of interest}

- Authors: Ji Won Lee and Geun Seog Song are employees of CJ HealthCare Corp.. The authors have indicated that they have no other conflicts of interest regarding the content of this article. The sponsor did not participate in the execution of the study or in the analysis of the data.

- Reviewers: Nothing to declare

- Editors: Nothing to declare

\section{References}

1. Maradey-Romero C, Fass R. New and future drug development for gastroesophageal reflux disease. J Neurogastroenterol Motil 2014;20:6-16 doi: 10.5056/jnm.2014.20.1.6

2. Schubert ML, Peura DA. Control of gastric acid secretion in health and disease. Gastroenterology 2008;134:1842-1860. doi: 10.1053/j.gastro. 2008.05.021.

3. Jang HJ, Choi MH, Shin WG, Kim KH, Chung YW, Kim KO, et al. Has peptic ulcer disease changed during the past ten years in Korea? A prospective multi-center study. Dig Dis Sci 2008;53:1527-1531.

4. Arikawa $\mathrm{Y}$, Nishida H, Kurasawa O, Hasuoka A, Hirase K, Inatomi N, et al. Discovery of a novel pyrrole derivative 1-[5-(2-fluorophenyl)-1-(pyridin3-ylsulfonyl)-1 H-pyrrol-3-yl]-N-methylmethanamine fumarate (TAK-438) as a potassium-competitive acid blocker (P-CAB). J Med Chem 2012;55:4446-4456. doi: 10.1021/jm300318t.

5. Jeon HK, Kim GH. Can Nocturnal Acid-breakthrough Be Reduced by Long-acting Proton Pump Inhibitors?. J Neurogastroenterol Motil 2017;23 145-148. doi: 10.5056/jnm17037.

6. Tytgat GN. Shortcomings of the first-generation proton pump inhibitors Eur J Gastroenterol Hepatol 2001;13:S29-S33.

7. Hori $Y$, Imanishi A, Matsukawa J, Tsukimi $Y$, Nishida $H$, Arikawa $Y$, et al. 1-[5-(2-Fluorophenyl)-1-(pyridin-3-ylsulfonyl)-1H-pyrrol-3-yl]-N-methylmethanamine monofumarate (TAK-438), a novel and potent potassiumcompetitive acid blocker for the treatment of acid-related diseases. J Pharmacol Exp Ther 2010;335:231-238. doi: 10.1124/jpet.110.170274.

8. Hatlebakk JG, Katz PO, Camacho-Lobato L, Castell DO. Proton pump inhibitors: better acid suppression when taken before a meal than without a meal. Aliment Pharmacol Ther 2000;14:1267-1272.

9. Teixeira MZ. Rebound acid hypersecretion after withdrawal of gastric acid suppressing drugs: new evidence of similitude. Homeopathy 2011;100: 148-156. doi: 10.1016/j.homp.2011.05.003. 
10. Hunt RH, Scarpignato $\mathrm{C}$. Potassium-competitive acid blockers (P-CABs): are they finally ready for prime time in acid-related disease?. Clin Trans Gastroenterol 2015;6:e119. doi: 10.1038/ctg.2015.39.

11. Han, Sung pil Safety, tolerablity, pharmacokinetics, and pharmacodynamics of escalating single and multiple oral doses of tegoprazan, a Novel potassium-competive acid blocker $\left(P_{-} C A B\right)$ in healthy male subjects. KDDW 2017, P-UG-075
12. Kagami T, Sahara S, Ichikawa H, Uotani T, Yamade M, Sugimoto M, et al. Potent acid inhibition by vonoprazan in comparison with esomeprazole, with reference to CYP2C19 genotype. Aliment Pharmacol Ther 2016;43: 1048-1059. doi: 10.1111/apt.13588.

13. Julious SA. Sample sizes for clinical trials with normal data. Stat Med 2004:23:1921-1986. 